\title{
Implementation of online assignment submission with instant feedback in a pharmacy course
}

\author{
Alamdar Hussain \\ School of Pharmacy, American University of Health Sciences, Signal Hill, California, USA
}

\author{
Keywords \\ Assignment \\ Biopharmaceutics \\ Blackboard \\ Instant grading \\ Online submission \\ Correspondence \\ Alamdar Hussain, PhD \\ Associate Professor \\ School of Pharmacy \\ American University of Health Sciences \\ Signal Hill \\ California \\ USA 90755 \\ ahussain@auhs.edu
}

\begin{abstract}
Objective: To implement online assignment submission with instant feedback in a biopharmaceutics course taught to professional pharmacy students, and to evaluate students' reception of the activity. Method: Online assignments equipped for immediate grading and feedback were administered on Blackboard to second year pharmacy students. A survey assessing students' reception of the effectiveness of this method was administered at the end of the semester. Results: Almost all the students (99.1\%) agreed or strongly agreed that the online assignments and feedback improved their understanding of the basic concepts in the course. Students $(98.8 \%)$ also felt that the use of computers in the course was worthwhile, and recommended their continued use. Conclusion: Online assignments with instant feedback offers a readily workable technique that students and this author perceive to have great value for enhancing student understanding in biopharmaceutics and related pharmacy courses.
\end{abstract}

\begin{abstract}
Introduction
Several pharmacy colleges throughout the country utilise online course management systems to facilitate student learning. Commonly used systems include WebCT and Blackboard, among others (Franic et al., 2004; Stone et al., 2004; Moridani, 2007; Lancester et al., 2011). While the benefits of these systems from a student's perspective include the accessibility of learning material outside of class meetings, the primary benefit for the instructor is the capability to manage these tasks with a single interface. Although several published articles have shown the use of these platforms in pharmacy education, there is very little information available with regard to the creation of online assignments with immediate feedback. The primary reason could be that majority of courses utilise group projects and may not require individual problem-based assignments (Romero et al., 2004). However, it is uncommon that courses such as biopharmaceutics and pharmacokinetics, which rely
\end{abstract}

heavily on mathematical principles, are taught without giving practice problems to students to solve.

Traditionally, students in pharmaceutics courses are provided with take-home assignments that involve sets of problems. After completing the assignment, students submit their work to the instructor for grading and feedback. Administering and grading several assignments throughout a course using the paper format can be burdensome and time consuming for the instructor. This burden often limits the number and length of assignments, especially if no additional support (e.g. graduate teaching assistants) is available. Furthermore, even if the instructor takes on the daunting task of grading several assignments, there will be a significant delay between the time when a student submits the assignment and the time feedback is received. Generally, students would be concentrating on the next topic by the time they receive feedback for a previous assignment. Therefore, to overcome these limitations and enhance active learning by students, 
online assignments with instant grading and feedback were instituted in a biopharmaceutics course taught by the author.

In pharmacy education, computer-based course management systems have been shown to be very useful in enhancing student learning (Andrew et al., 2000; Klockars et al., 2003; Freeman et al., 2006). While these platforms can be used to generate assignments, a few instructors have developed online modules for administering assignments. For instance, Mehvar has developed a web-based course for teaching pharmacokinetics, which incorporates online submission of assignment (Mehvar, 1999). Students who used the online submission process scored approximately $10 \%$ higher $(p<0.05)$ than those who used the paper format. The primary advantages of such programs are the creation of unique assignment for each student and the opportunity to generate unlimited practice problems (Mehvar, 1999; Mehvar, 2000).

Developing a complete interactive web-based learning package not only involves significant time commitment by the instructor, but the task may be intimidating to those who have little experience with web-based designs. Therefore, the aim of the present work was to use Blackboard, a simple course delivery tool, for administering online assignments in a biopharmaceutics course.

\section{Methods}

Biopharmaceutics is a required three-credit hour course offered in the first term of the second year of the professional pharmacy programme. During the autumn semester, the course was organised into 3750 minute lectures. Student comprehension of the course material was assessed using the following components administered during the semester: ten unannounced quizzes, 12 assignments, and four examinations (including the final exam). The quizzes and exams were conducted in-class using the pencil and paper multiple choice questions format, while the assignments were posted on Blackboard for online completion by the student outside of the classroom.

\section{Online assignments}

For most topics covered in the lecture material, assignments relevant to the topic were created. These assignments constituted $30 \%$ of total course points. Students were required to work on assignment problems and submit their responses during the allotted time period. Factors that were taken into consideration while designing and implementing assignments were students' comprehension of the subject matter and problem-solving skills, including maths. Two sets of practice problems (paper format) along with their solutions were also created for each assignment and made available on Blackboard. Although the assignments were due within one or two days of completion of the lecture topic, the assignments and practice sets were made available several days before the classroom completion of a particular topic so that students capable of working on their own could complete the assignment using practice sets as the guide. Students were strongly urged to work on the practice sets before attempting the graded assignment. The due dates for submission of each assignment were mentioned in the class schedule.

Students were provided with instructions on general navigation and the completion process in the assignment folder of Blackboard. Although a given assignment was available for several days, once a student accessed the portal, the submission process had to be completed within three hours. The time restriction was placed to provide a psychological atmosphere of a timed test and to facilitate students in working with online exams in the future. To prevent a student from accidentally starting the assignment, access to the test page was restricted by a password.

Each assignment consisted of ten questions, and students were presented with one question at a time on the computer screen (Figure 1). At the completion of the assignment, the student's answer, the correct answer, and the score obtained on the assignment were presented on the computer screen. At the same time, the scores were automatically added to the course's electronic grade book.

\section{Assessment}

At the completion of the course, a paper and pencil survey instrument consisting of questions pertaining to the online assignment section of the course was administered in class. The instrument also contained a section for additional comments, and students were instructed to comment exclusively about online assignments. Students completed the survey anonymously and placed it in a folder circulated in the classroom. The survey consisted of quantitative questions using a five-point Likert scale using the rating of 1) Strongly Disagree; 2) Disagree; 3) Neutral; 4) Agree; and 5) Strongly Agree. The use of a Likert scale for recording students' perceptions of a teaching method has been reported by others (Mehvar, 2000; Klockars et al., 2003; Freeman et al., 2006). 
Relevant statistical tests were performed using GraphPad Prism version 4. The data collection process was determined to be exempt by the Institutional Review Board of the University.

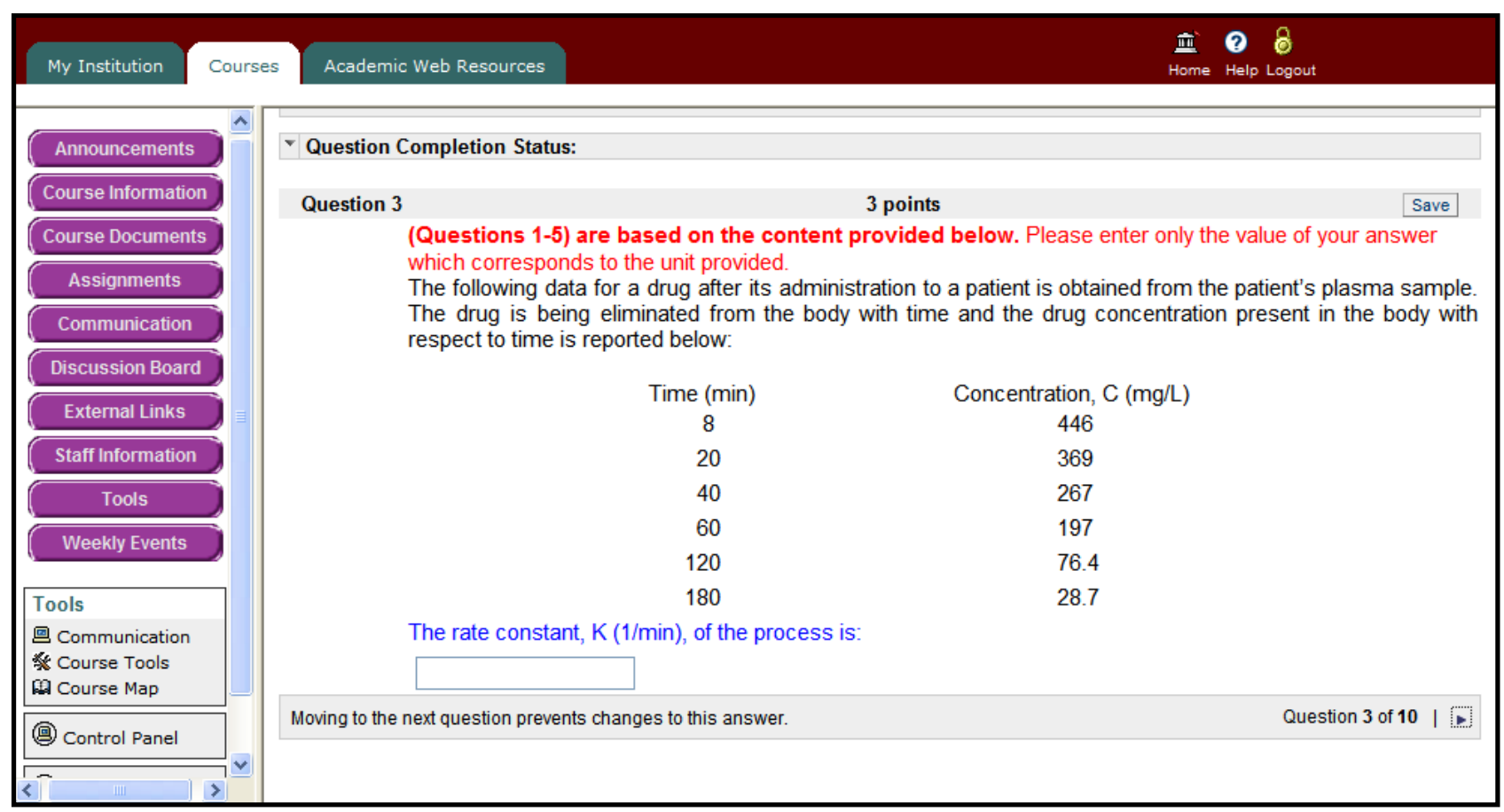

Figure 1: A screen snapshot of an assignment page for students

\section{Results}

Eighty six out of 87 students enrolled in the course completed the survey instrument administered. In general, the response of students to the online assignments was overwhelmingly positive. For 14 questions, students gave an extremely favourable rating (Table I), while for five questions, they gave a moderate or poor rating (Table II). All the students, except one, agreed (35.2\%) or strongly agreed $(63.9 \%)$ that the use of assignments and practice sets improved their understanding of the course. The response to this question also received the third-highest average rating on the survey instrument (Question 13, Table I). The option of including a range within which a submitted answer on the assignment would be correct received the students' highest average rating (Question 8, Table I). This was followed by the statement that the assignments kept them abreast with the course material covered (Question 2, Table I). Other statements that received a high average rating (> 4.5) from students were the option of completing the assignments at their convenience and receiving instant feedback, ease of the online submission process, and support for continuing use of computers for the course in the future (Table I).

Despite the generally very positive feedback concerning online assignments, it was surprising to discover that only a small percentage of students $(18.6 \%)$ wished to take quizzes and exams online in a classroom setting. This response also received one of the lowest numerical average ratings (Question 3, Table II). The temptation to commit academic dishonesty on assignments received the lowest student rating on the survey instrument (Question 5, Table II).

Besides the questionnaire statements, students also had the opportunity to include additional comments of their own on the survey. In agreement with the Likert-scale responses, the comments included by the students were mostly positive. Although there were several assignment-related comments made on the survey, only a representation of commonly observed comments is provided here for brevity (Table III). 
Table I: Student evaluation of survey questions that received good or excellent rating*

\begin{tabular}{|c|c|c|}
\hline Question & & Mean $^{+} \pm$SD \\
\hline 1. & Including online assignments as part of the course increased my interest in the course & $4.04 \pm 0.72$ \\
\hline 2. & With the set-up of assignments periodically, I was forced to keep up with the course material covered & $4.65 \pm 0.48$ \\
\hline 3. & I liked the idea of submitting assignments at my convenience and getting instant score and feedback & $4.62 \pm 0.49$ \\
\hline 4. & The online submission process was very easy & $4.53 \pm 0.61$ \\
\hline 5. & I usually faced no problems in submitting the assignments except when Blackboard was down & $4.45 \pm 0.71$ \\
\hline 6. & I found no organisational deficiencies in the setup of assignments & $4.37 \pm 0.81$ \\
\hline 7. & I liked the idea of incorporating a few conceptual questions on the assignments & $4.22 \pm 0.76$ \\
\hline 8. & I liked the idea of having a range within which a number entered would be correct & $4.78 \pm 0.56^{\ddagger}$ \\
\hline 9. & The credit for assignments was appropriate for the amount of work done & $4.38 \pm 0.63$ \\
\hline 10. & The use of computers assisted me in taking responsibility for my own learning & $4.13 \pm 0.72$ \\
\hline 11. & I would recommend online submission of assignments with instant feedback for courses that involve math & $4.34 \pm 0.74$ \\
\hline 12. & I am more familiar with using Excel for graphing data than I was before & $4.41 \pm 0.72$ \\
\hline 13. & The practice sets and assignments improved my understanding of the basic concepts in the course & $4.62 \pm 0.56$ \\
\hline 14. & Overall, the use of computers for this course is worthwhile and should be continued in the future & $4.51 \pm 0.52$ \\
\hline
\end{tabular}

*Likert-scale; $1=$ Strongly Disagree, 2=Disagree, 3=Neutral, 4=Agree, 5=Strongly Agree

${ }^{+} N=86$ responses except for question 8

${ }^{\ddagger} N=85$ responses

Table II: Student evaluation of survey questions that received moderate or poor rating*

\begin{tabular}{|c|c|c|}
\hline \multicolumn{2}{|c|}{ Question } & \multirow{2}{*}{$\begin{array}{l}\text { Mean }^{+} \pm \text {SD } \\
3.30 \pm 1.37\end{array}$} \\
\hline 1. & $\begin{array}{l}\text { I usually attempted to solve the practice } \\
\text { sets before the class }\end{array}$ & \\
\hline 2. & $\begin{array}{l}\text { I usually waited until the last few hours } \\
\text { before the due time to submit the } \\
\text { assignment }\end{array}$ & $2.84 \pm 1.17$ \\
\hline 3. & $\begin{array}{l}\text { I wish the quizzes and exams were also } \\
\text { online in the classroom setting }\end{array}$ & $2.50 \pm 1.12$ \\
\hline 4. & $\begin{array}{l}\text { After taking online tests, I am less } \\
\text { apprehensive of taking online exams in the } \\
\text { future }\end{array}$ & $3.80 \pm 0.93$ \\
\hline 5. & $\begin{array}{l}\text { I was tempted a few times to cheat on the } \\
\text { assignment when I really didn't have time } \\
\text { to work on the practice sets }\end{array}$ & $2.49 \pm 1.23$ \\
\hline
\end{tabular}

\section{Table III: Student comments regarding online} assignments*

\begin{tabular}{l}
\hline \multicolumn{2}{l}{ Student comments } \\
\hline 1. I liked it, and it helped me learn \\
2. The concept questions were harder than the problems \\
3. I think the value of the assignments was very high \\
4. Online assignments worked really well \\
5. I would like to be able to go back to previous questions to \\
*Representative of 13 comments made on the survey instrument
\end{tabular}

\section{Discussion}

It is well known that without substantial practice and active student involvement, significant learning and retention rarely occurs (Svinicki et al., 2014). This issue becomes paramount when teaching courses involving math. Nevertheless, without an accompanying incentive involved, less-motivated students may choose not to work on the practice problems. Therefore, the idea was to generate graded assignments based on practice problems in order to involve students actively. Without a robust mechanism in place, grading all student assignments for every topic and providing timely feedback becomes an overwhelming task for the instructor. The purpose of the current project was to utilise Blackboard for easy generation of online assignments with instant feedback and grading feature in a biopharmaceutics course. This method was experimented in two consecutive autumn semesters at the College of Pharmacy; however, the survey was administered only in the second year.

The results of student evaluation suggest that the inclusion of assignments greatly increased student understanding of the concepts studied in the course. The Pearson correlation between the student scores earned for online assignments and overall course grade was significant $(p<0.001)$, with a good relationship between the above two parameters $(r=0.46)$. Only one out of 86 students who responded to the survey strongly disagreed that the practice sets, and assignments improved his understanding of the course. This student also strongly disagreed with the statement that there 
were no organisational deficiencies in the setup of assignments. It follows logically that because this student did not find the setup easy, the student did not benefit from online assignments.

In general, students liked the option of allowing a range for an answer within which a value entered would be correct. Usually, when maths is involved, individuals end up with their final answers differing slightly from each other as a result of rounding, although these differences may be statistically and clinically insignificant. Therefore, for the system to realise that all submitted values within certain limits were correct, a range was provided for the answer.

It is a common observation that students feel more enthusiastic about their work when they receive feedback in a timely manner (Mehvar, 1999). The instant feedback and grading feature seems to have exceeded students' expectations of turnaround time for grading assignments. Most students expressed that when they re-worked the problem after knowing the correct answer, they figured out where they had gone wrong. Surprisingly, only a relatively small proportion of students expressed interest in taking exams and quizzes online in a classroom setting. The most likely reason for this apparent paradox is that students were not required to bring laptop computers to class. In fact, a mandatory student laptop policy in the college did not exist until a later admission cycle, and many of these students were using college, library, or home computers for completing the assignments.

In the survey, students generally opined that an inclination towards academic dishonesty with this format does not present a serious issue. Although the evaluation was anonymous, there still seems a strong likelihood that some students feared to answer honestly, envisioning potential negative consequences based on their candid response. Therefore, caution should be exercised in interpreting responses to this question on the survey. Nonetheless, the author noticed that students who performed well on the assignments also typically scored well on in-class tests, so it is less likely that the majority resorted to cheating. Students disagreed that they waited until the last few hours to submit the assignment (Question 2, Table II). This implies the eagerness of students to access and submit the online assignment as early as possible.

Some students also took the opportunity to express their opinions in the form of personal comments on the survey instrument (Table III). In general, the statements for completing and the usefulness of assignments were very encouraging. Two students expressed their disapproval for not having the option of going back to a previous question to rectify the answer during the submission process. It should be realised that
Blackboard does have the option to let the user backtrack. If the instructor wishes, students can be allowed to go back and change an answer for a previously submitted question before the final submission. Two students felt that the portion of grade allocated for the assignments was high; however, the overall class (96.5\%) thought that the allotted credit was appropriate (Question 9, Table I). Given that it required several hours of student's study time to work on each assignment, the instructor feels the allocation was appropriate.

However, the findings from the current study must be interpreted cautiously. There was no pre-evaluation survey administered to students. So, it was not possible to determine what perceptions students had of online assignments before taking the survey instrument at the end of the semester. The author would bring attention to studies such as those presented in the review by Van der Kleij and authors (2015). Those studies provide useful techniques in assessing students' learning using a computer-based system and are from various disciplines of science.

Further, there are some quality instruments available such as the medical education research study quality instruments (MERSQI) and the Newcastle-Ottawa scaled education (NOS-E) (Reed et al., 2007; Cook et al., 2015). They involve principles of research quality that are not discipline-specific and would be appropriate to apply to education studies in any discipline (not just pharmacy). Such instruments should be consulted for any future studies like the one reported in this work were to be performed.

\section{Limitations}

A major limitation of the current online assignment setup is that all students received the same assignment. The system does have the option for randomisation of questions, but basically, the test will be the same regardless of the order in which students receive questions. Therefore, performing academic dishonesty by a student is not reduced using this approach compared to the paper format of a take-home assignment. As problem-solving is integral to the concept of the course and can not be eliminated, one option to cope with academic dishonesty is to assign a low proportion of the course grade to online assignments. In this way, even if a student resorts to cheating, he or she would be relatively unlikely to leverage this dishonesty for achieving a passing grade in the course. A second option is to let the system record the completion time for the assignment. Accordingly, the instructor will know when a student has taken an 
unusually short time to complete the assignment. A third option is to give the feedback only after all the students have submitted their homework. This option, unfortunately, nullifies the core purpose of real-time learning, eliminating the strong benefits discussed above. An ideal arrangement would be to create a question database so that every student receives a different assignment (Mehvar, 2000)

Another limitation of using this approach would be for courses, which do not involve a significant amount of math. An instructor's question bank may soon be depleted if the instructor intends to test only conceptual questions using this setup. Consequently, a significant amount of time will have to be spent on creating different questions for the quizzes and exams. The applicability to maths courses is that a change in the value of a few parameters in the problems would lead to the generation of a new problem set.

\section{Conclusion}

Primarily, course management systems are used for posting class materials, announcements and grades, and reports of using their full capabilities are limited. Certainly, while not necessarily optimal for all pharmacy courses, the use of such systems for creating assignments with the capability of instant feedback and grading in courses that involve math is highly desirable. The creation of such assessments requires minimal computer knowledge and promotes student learning and retention of concepts. The method may be used as a tool in active learning strategies in courses that involve maths.

\section{Acknowledgement}

The work was performed at the University of Louisiana College of Pharmacy, Monroe, Louisiana, United States of America.

\section{References}

Andrew, M. (2000). Use of web-based learning to teach pharmacy undergraduates. The Pharmaceutical Journal, 265, 558-562

Cook, D.A., \& Reed, D.A. (2015). Appraising the quality of medical education research methods: The medical education research study quality instrument and the Newcastle-Ottawa scale-education. Academic Medicine, 90(8), 1067-1076. https://doi.org/10.1097/ACM.0000000000000786

Franic, D.M. (2004). Promoting learning in a health care systems course by multiple teaching methods including internet-based quizzes. American Journal of Pharmaceutical Education, 68(5), Article 119. https://doi.org/10.5688/aj6805119

Freeman, M.K., Schrimsher, R.H., \& Kendrach, M.G. (2006). Student perceptions of online lectures and WebCT in an introductory drug information course. American Journal of Pharmaceutical Education, 70(6), Article 126. https://doi.org/10.5688/aj7006126

Klockars, S.J., Blair, M.M., Mazur, J.N., Ragucci, K.R., \& Fermo, J. (2003). Assessment of web-based applications for ambulatory care rotations. Annals of Pharmacotherapy, 37(12), 1785-1788. https://doi.org/10.1345/aph.1D165

Lancaster, J.W., McQueeney, M.L., \& Van Amburgh, J.A. (2011). Online lecture delivery paired with in class problembased learning: Does it enhance student learning? Currents in Pharmacy Teaching and Learning, 3(1), 23-29. https://doi.org/10.1016/j.cptl.2010.10.008

Mehvar, R. (1999). Online, individualized, and interactive pharmacokinetic scenarios with immediate grading and feedback and potential for use by multiple instructors. American Journal of Pharmaceutical Education, 63(3), 348353

Mehvar, R. (2000). Creation of a dynamic question database for pharmacokinetics. American Journal of Pharmaceutical Education, 64(4), 441-445

Moridani, M. (2007). Asynchronous Video Streaming vs. Synchronous Videoconferencing for Teaching a Pharmacogenetic Pharmacotherapy Course. American Journal of Pharmaceutical Education, 71(1), Article 16. https://doi.org/10.5688/aj710116

Reed, D.A., Cook, D.A., Beckman, T.J., Levine, R.B., Kern, D.E., \& Wright, S.M. (2007). Association between funding and quality of published medical education research. Journal of American Medical Association, 298(9), 1002-1009. https://doi.org/10.1001/jama.298.9.1002

Romero, R.M., Eriksen, S.P., \& Haworth, I.S. (2004). A decade of teaching pharmaceutics using case studies and problembased learning. American Journal of Pharmaceutical Education, 68(2), 1-10

Stone, V.L., Bongiorno, R., Hinegardner, P.G., \& Williams M.A. (2004). Delivery of web-based instruction using blackboard: a collaborative project. Journal of Medical Library Association, 92(3), 375-377

Svinicki, M.D., \& McKeachie, W.J. (2014). McKeachie's teaching tips: strategies, research, and theory of college and university teachers (pp 154-196), Belmont, CA: Cengage Learning

Van der Kleij, F.M., Feskens, R.C.W., \& Eggen, T.J.H.M. (2015). Effects of feedback in a computer-based learning environment on students' learning outcomes: A metaanalysis. Review of Educational Research, 85(4), 475-511. https://doi.org/10.3102/0034654314564881 